Dieses Dokument ist eine Zweitveröffentlichung (Verlagsversion) /

This is a self-archiving document (published version)

„Dieser Beitrag ist mit Zustimmung des Rechteinhabers aufgrund einer (DFG-geförderten) Allianzbzw. Nationallizenz frei zugänglich."

This publication is openly accessible with the permission of the copyright owner. The permission is granted within a nationwide license, supported by the German Research Foundation (abbr. in German DFG).

https://www.nationallizenzen.de
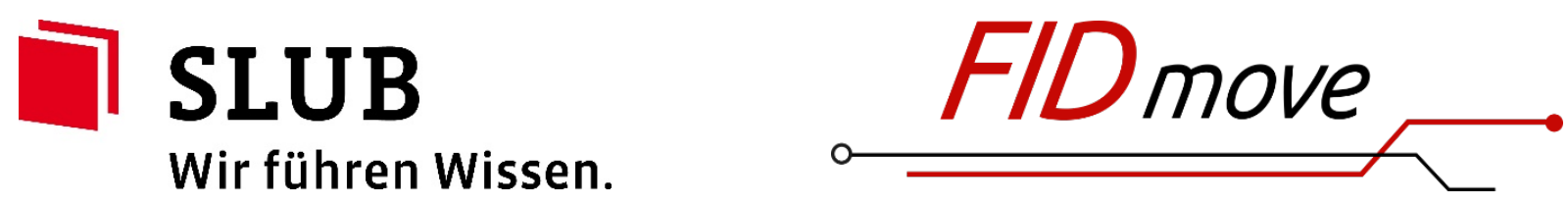


\title{
Active flow control at a 1.5-stage low-speed research compressor with varying rotor tip clearance
}

\author{
M Künzelmann*, R Urban, R Mailach, and K Vogeler \\ Technische Universität Dresden, Institute of Fluid Mechanics, Dresden, Germany
}

The manuscript was received on 6 July 2011 and was accepted after revision for publication on 6 July 2011.

DOI: $10.1177 / 0957650911418150$

\begin{abstract}
The stable operating range of axial compressors is limited by the onset of rotating stall and surge. Mass injection upstream of the tip of an axial compressor rotor is a stability enhancement approach which can be effective in suppressing stall in tip-critical rotors, and thus increasing the operating range of compressors. In this article, investigations on active flow control related to the rotor tip gap sensitivity are discussed. The experiments were performed in a 1.5-stage low-speed research compressor. Measurements at part speed (80 per cent) and full speed (100 per cent) with varying injection rates are discussed. These tests were performed for two rotor tip clearances of 1.3 per cent and 4.3 per cent of rotor blade tip chord. Results on the compressor map, the flow field as well as transient measurements to identify the stall inception are discussed. Supplementary, the numerical results are compared to the experiments based on the configuration with the greatest benefit in operating range enhancement.
\end{abstract}

Keywords: axial compressor, active flow control, blowing, rotating stall inception

\section{INTRODUCTION}

The stable operating range of axial compressors is limited by the onset of rotating stall or surge. Such critical flow conditions must be avoided because they compromise the safe operating caused by higher vibrations and high thermal loading of the blades and other machine components. This will lead to reduction of fatigue life or even a destruction of engine parts. Hence, an adequate distance between working and surge lines must be kept, known as surge margin. This decreases the available operating range and the ability to increase the efficiency of stationary gas turbines and jet engines. Thus, a high motivation is given to develop techniques to extend the operating range of compressors. Furthermore, a challenge in development of compressors is to reduce the number of stages and reduce weight in order to lower fuel consumption. This leads to higher blade loading and limitation of operating range. Thus, enhancement of

* Corresponding author: Technische Universität Dresden, Institute of Fluid Mechanics, 01062 Dresden, Germany.

email: Mario.Kuenzelmann@web.de compressor stability and improvements in stall and surge margin are required to be able to operate well in off-design conditions.

For all the mentioned reasons, there has been an increasing effort over the past decades to develop techniques to handle these problems. There are two significant methods regarding flow control characterized by Mattiske [1]: passive and active flow control techniques. Passive methods compromise three-dimensional (3D) shaped blading or changes in pitch and stagger angle. Active methods include casing treatments and flow control using steady or unsteady injection of air. The first concept to enhance compressor stability was a 1950 patent filed by Wilde [2] of RollsRoyce Limited using a recirculation method. The idea was to bleed air from aft stages and injected it upstream of the inlet guide vanes at the compressor casing. The first experimental investigations regarding stall improvement were performed in the early 1960s by the NASA Lewis Research Center. Koch and Smith [3] reported that a steady mean flow injection has a strong positive impact on the stable operating range. The authors also evaluated the bleeding technique being not so effective for enhancing stability compared to their injection methods. Suder et al. [4] studied the impact of jet injection and its arrangement around 
the circumference of the compressor and identified that the choked flow in the injector established the maximum extent in operating range. Furthermore, the number of injectors and the total injected mass flow could be reduced compared to the setup used by Weigl et al. [5].

A further concept is the active control of compressor instabilities initiated by Epstein et al. [6]. Rotating disturbances appear in the unsteady flow regime near stall. A signal in phase opposition is superimposed to damp such perturbations. Day [7, 8] and D'Andrea et al. [9] implemented this concept at a low-speed compressor using blowing methods. Weigl et al. [5] demonstrated the effective control of the first and second harmonics of pre-stall perturbations. The authors reported the need of controlling the onedimensional (1D, surge) and two-dimensional (2D, rotating stall) perturbations in order to increase the compressor operating range. The tests established a slightly more effective unsteady blowing technique compared to steady injection. This behaviour has also been reported by Strazisar et al. [10]. The main key to enhance operating range is caused by increasing the circumferential mass-averaged axial velocity at the rotor tip gap due to flow injection, Suder et al. [4] and Strazisar et al. [10].

The development and implementation of such concepts in real engines is still in progress. There are serious difficulties in feedback control due to the high speed range of multistage compressors. A change in speed correlates with a change in aerodynamic loading and shifts the origin of pre-stall perturbations between the stages. Only a few scientists tested active flow control at real engines. Ffowcs Williams et al. [11] report about investigations in a radial compressor of a stationary gas turbine and Freeman et al. [12] in an axial compressor of a jet engine. Scheidler and Fottner [13] could establish a range extension in a Larzac-04-C5 engine and mentioned successful restabilization tests. Bindl et al. [14] developed a stall detection algorithm in combination with an active compressor stabilization system using the same test rig. An overview regarding the history of developing active and passive flow control techniques and recent investigations is given by Hathaway [15].

The main focus of this article is to discuss the behaviour of a low-speed compressor with varying rotor tip clearance and active flow control in order to extend the operating range and to increase the efficiency using steady flow injection. Therefore, a special injector was developed which does not protrude in the main flow channel and has a suitable axial distance to the leading edge of the rotor. Furthermore, the pre-stall behaviour and the influence of modal waves are shown. For this, some microphone arrays were applied at the compressor casing.

In some publications, the wall jet flow is predicted using estimations based on CFD results, like Strazisar et al. [10]. In this study, the axial velocity component of the injected air was measured using a hot wire probe to gather information about the unsteady behaviour of the energized flow upstream of the rotor tip and after passing the rotor blade row. A new topology was developed to have access to the information of the time resolved flow field within the rotor passage. For this purpose, CFD calculations were carried out using the commercial software package FINE $^{\mathrm{TM}} /$ Turbo (NUMECA International). The model has the ability to estimate the surge margin extension close to the experiments.

\section{TEST RIG}

The experiments discussed here were performed in LSRC of Technische Universität Dresden, which was put into operation in 1995. The standard 4.5-stage compressor was build up as a single stage machine preceeded by an inlet guide vane row shown in Fig. 1 .

The results discussed in this article are for the datum blading of this compressor with cantilevered stator vanes (build A2). This blading is based on the profiles of a middle stage of a jet engine high-pressure compressor and consists of 51 inlet guide vanes, 83 stator vanes, and 63 rotor blades. Detailed descriptions of the compressor and selected results of standard measurements are given by Sauer et al. [16], Boos et al. [17], and Künzelmann et al. [18]. Table 1 gives a summary of the main design parameters. The vertical arrangement of the stages ensures a good access to all measuring planes and constant radial gaps of the blades. The inlet flow is symmetrical due to the arrangement of the compressor in the centre of the hall.

The power consumption is measured using a precision torque meter. The mass flow is determined at the inlet nozzle and is adjusted by a throttle at the outlet. The compressor shaft speed is corrected with the total inlet temperature. The rotational speed of the compressor is adjusted with an accuracy of \pm 0.05 per cent. Power input to the compressor is determined by a precision torquemeter having an accuracy of \pm 0.07 per cent of torque at the design point.

\subsection{Secondary air system}

The pressure rise of the Dresden LSRC is too low to realize a flow recirculation from the compressor outlet. Hence, an SAS was required to provide the air to be injected. A multifunctional system was supplemented to the LSRC which can support 


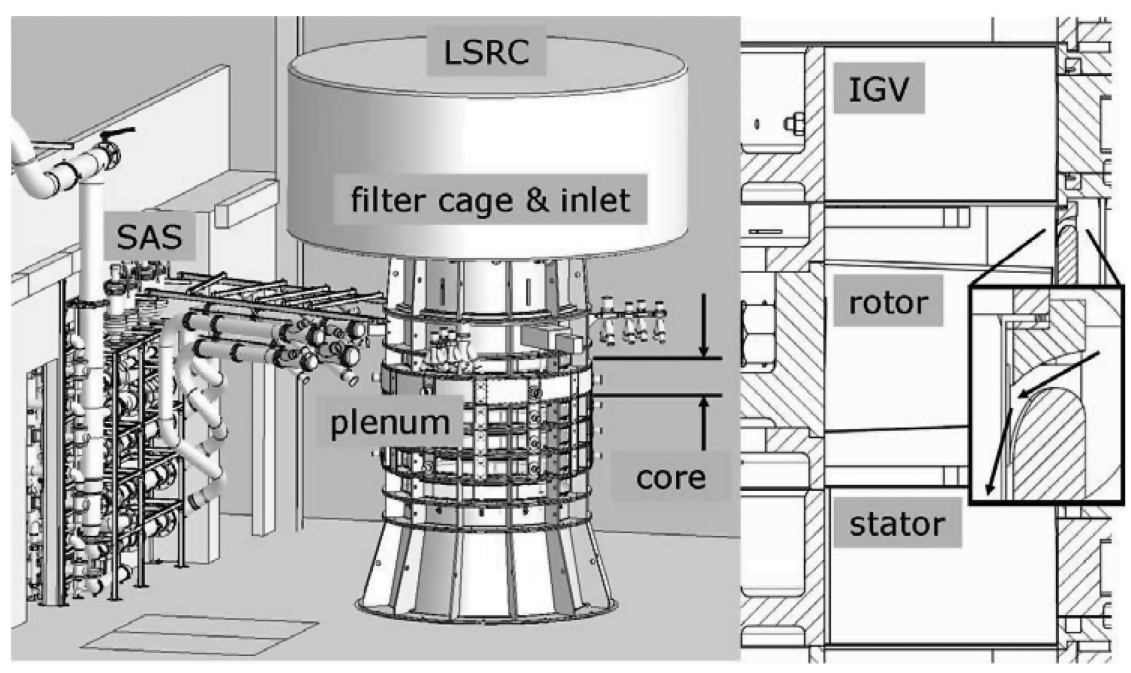

Fig. 1 Dresden LSRC: secondary air system and sectional view of blading and injector

Table 1 Dresden LSRC - design parameters

\begin{tabular}{|c|c|c|c|}
\hline \multicolumn{4}{|l|}{ LSRC - 1.5 stage } \\
\hline \multicolumn{4}{|l|}{$\begin{array}{l}\text { Reynolds number, rotor } \\
\text { inlet. MS }\end{array}$} \\
\hline $\begin{array}{l}\text { (based on rotor chord } \\
\text { length) }\end{array}$ & $5.7 \cdot 10^{5}$ & & \\
\hline $\begin{array}{l}\text { Mach number, rotor } \\
\text { inlet, MS }\end{array}$ & 0.22 & & \\
\hline Design speed & $1000 \mathrm{r} / \mathrm{min}$ & & \\
\hline Design mass flow & $25.35 \mathrm{~kg} / \mathrm{s}$ & & \\
\hline Flow coefficient $\varphi$, DP & 0.553 & & \\
\hline Enthalpy coefficient $\Psi$, DP & 0.794 & & \\
\hline Hub diameter & $1260 \mathrm{~mm}$ & & \\
\hline Hub-to-tip ratio & 0.84 & & \\
\hline \multirow{2}{*}{$\begin{array}{l}\text { Axial gaps between } \\
\text { blade rows, MS }\end{array}$} & $32 \mathrm{~mm}$ & & \\
\hline & IGV & Rotor & Stator \\
\hline Blade number & 51 & 63 & 83 \\
\hline Chord length, MS & $80 \mathrm{~mm}$ & $110 \mathrm{~mm}$ & $89 \mathrm{~mm}$ \\
\hline $\begin{array}{l}\text { Stagger angle, MS } \\
\quad \text { (versus circumference) }\end{array}$ & $82.8^{\circ}$ & $49.3^{\circ}$ & $64.0^{\circ}$ \\
\hline Solidity, MS & 0.941 & 1.597 & 1.709 \\
\hline
\end{tabular}

four stages. It is possible to handle blowing or bleeding or a combination of both. The mass flows can be controlled separately with respect to the different pressure levels of each stage. Two external sources are available to supply the system with auxiliary air, an external radial compressor or a set of screw compressors. The mass flow is determined using an ultrasonic flow meter (Elster Instromet) with an accuracy of less than 1 per cent. The system consists of four independent strands for each stage for the standard compressor. The strands are controlled with a set of eight electro-pneumatic valves.

\subsection{Injector geometry}

The developed injectors are part of the compressor casing and were uniformly distributed in the circumferential direction for each configuration. An outer coverage is mounted to create an annular plenum with the inlet ports and pipes shown in Fig. 1. Suder et al. [4] used injectors located two rotor chords upstream of the rotor leading edge and protruded into the main flow path. In typical multistage compressors, the distance between the rows is just a fraction of a chord length. The aim is to minimize this distance reducing the overall length and thus the engine weight. The effort was to develop injectors capable of generating a wall jet along the compressor casing and to minimize the upstream distance between slot and rotor leading edge, which was achieved to be about 10 per cent of rotor tip chord. The designed elliptical curvature is tangential to the main flow path and able to establish globally the Coanda effect at the inner compressor casing upstream of the rotor tip. Also, the injector designed by Strazisar et al. [10] is based on the Coanda effect. The incoming jet is kept attached to the flow path near the casing.

The advantage is that there are no parts which protrude in the annular flow path. The width of each injector is 4 degrees in the circumferential direction. This means a coverage of 5.5 per cent, 11 per cent, and 22 per cent of the whole circumference depending on the number of injectors (Table 2). The ratio between the number of blades and injectors results in 12.6, 6.3, and 3.15 .

\section{EXPERIMENTAL INVESTIGATIONS}

Table 2 gives an overview of the investigated matrix of the five different configurations. The three main parameters are the rotor tip clearance, the number of injectors and the blowing rates referred to the 
Table 2 Configurations and measuring matrix

\begin{tabular}{llll}
\hline Configuration & $\begin{array}{l}\text { Tip clearance } \\
\text { ratio [\%] }\end{array}$ & $\begin{array}{l}\text { Blowing } \\
\text { ratios [\%] }\end{array}$ & Injectors \\
\hline A18-01 & 1.3 & 0.80 and 1.10 & 10 \\
A18-02 & 1.3 & 1.10 and 2.00 & 20 \\
A18-03 & 1.3 & 0.55 and 0.70 & 5 \\
A18-04 & 4.3 & 1.10 and 2.00 & 20 \\
A18-05 & 4.3 & 0.80 and 1.10 & 10 \\
\hline
\end{tabular}

compressor design mass flow. The configurations with nominal tip clearance (1.3 per cent of rotor tip chord) are denoted A18-01 up to A18-03. In configurations A18-04 and A18-05, the clearance was increased to 4.3 per cent of rotor tip chord with a length of $116 \mathrm{~mm}$.

\subsection{Compressor characteristics}

The compressor characteristic was determined for two different speedlines $(\zeta=0.80, \zeta=1.00)$ using wall pressure taps in all axial gaps located at casing and hub. The total temperature and total pressure rakes are located at the inlet and outlet. All pressures are measured using pressure transducers (ZOC system) having an accuracy of \pm 0.02 per cent of full scale. The efficiency is accurate to be within \pm 0.22 per cent. Total temperatures are determined with an accuracy of $0.1 \mathrm{~K}$. With the calibrated compressor inlet nozzle the deviation in mass flow is less than 0.05 per cent. The flowrate coefficient $\xi$, the pressure ratio $\pi$, and the speed coefficient $\zeta$ are determined using relations (1). The overall efficiency $\eta_{(M)}$ considers the total pressure loss of the injectors. The pressure at the inner casing wall is denoted with $p_{\text {wall }}$, equation (2)

$$
\begin{aligned}
& \zeta=\frac{n / \sqrt{T_{t, i n}}}{n / \sqrt{T_{t, i n, D P}}} \\
& \xi=\frac{\dot{m}_{\text {in }} \cdot \sqrt{T_{t, \text { in }}} / p_{t}}{\dot{m}_{D P} \cdot \sqrt{T_{t, i n, D P}} / p_{t, D P}}+\frac{\dot{m}_{\text {inj }}}{\dot{m}_{D P}} \quad \pi=\frac{p_{t, \text { out }}}{p_{t, \text { in }}} \\
& \eta_{(M)}=\frac{\left(\dot{m}_{i n}+\dot{m}_{i n j}\right) \cdot\left(h_{t, s, o u t}-h_{t, s, i n}\right)}{P_{(M)}} \\
& -\frac{\frac{\kappa}{\kappa-1} \cdot R \cdot T_{p l} \cdot\left[\left(\frac{p_{p l}}{p_{\text {wall }}}\right)^{\frac{\kappa-1}{\kappa}}-1\right]}{P_{(M)}} \cdot \frac{\dot{m}_{i n j}}{\dot{m}_{i n}+\dot{m}_{i n j}}
\end{aligned}
$$

The total injected mass flow was kept constant for the whole operating range. For all investigations, a reference speed line without injection was determined. An extension in operating range could be established for all investigated configurations. In principle, the range extension and efficiency is higher for decreasing compressor speed caused by
Table 3 Benefit in points of efficiency - design point

\begin{tabular}{lllll}
\hline Configuration & $\begin{array}{l}\Delta \eta_{(M)} \\
(\zeta=0.8)\end{array}$ & $\begin{array}{l}\Delta \eta_{(M)} \\
(\zeta=1.0)\end{array}$ & $\begin{array}{l}\text { Blowing } \\
\text { ratio [\%] }\end{array}$ & Injectors \\
\hline A18-02 & 1.18 per cent & 2.08 per cent & 2.00 & 20 \\
A18-04 & 2.83 per cent & 2.24 per cent & 2.00 & 20 \\
A18-05 & 2.52 per cent & 1.95 per cent & 1.10 & 10 \\
\hline
\end{tabular}

lower turning, pressure ratio, flow velocities, and lower Reynolds numbers as well.

Table 3 shows the efficiency for the configurations with significant benefit. The improvement in efficiency for the compressor with nominal tip gap increases with shaft speed and is reduced near stability limit achieving almost the same values compared to the reference case (no figure). This behaviour is reversed with increased rotor tip gap. Here, the maximum benefit is achieved at off-design $(\zeta=0.80$, $\xi=0.65)$ condition for build A18-04 with approximately 6 per cent points of efficiency (Fig. 2). Furthermore, the efficiency line at design speed of build A18-04 with increased tip gap and blowing becomes nearly identical to that of build A18-02 with nominal tip gap without blowing. Hence, the effect of increased loss for the large tip clearance could be neglected. The established enhancement in operating range is described using the following equation introduced by Cumpsty [19]. The definition of SM which retains the physical significance of the outlet flow function but uses the measured inlet flow function is given by

$$
S M=1-\left[\frac{\pi_{D P}}{\pi_{N S}} \cdot \frac{\xi_{N S}}{\xi_{D P}}\right]
$$

Furthermore, Suder et al. [4] and Strazisar et al. [10] considered the mass-averaged axial velocity to be the significant criterion for effective stability improvement. Surge margin improvement relative to the surge margin of the reference case is given in Fig. 3 for design speed $(\zeta=1.0)$.

The mass-averaged axial velocity $c_{a x, m a}$ is related to rotor tip velocity $u_{t i p}$. The diagram shows the relation between injected mass flow, number of injectors, and two different blowing rates (compare Table 2).

The results using tip injection at design speed and nominal tip gap reveal the same trend compared to the data reported by Suder et al. [4]. Minimum range extension was measured using five injectors although the highest momentum during injection was established. There is a marginal difference between 10 injectors and double the momentum compared to 20 injectors while keeping the injected mass flow almost constant. The characteristic for nominal gap suggests that more than 20 injectors will not be necessary. This behaviour changes when the compressor 

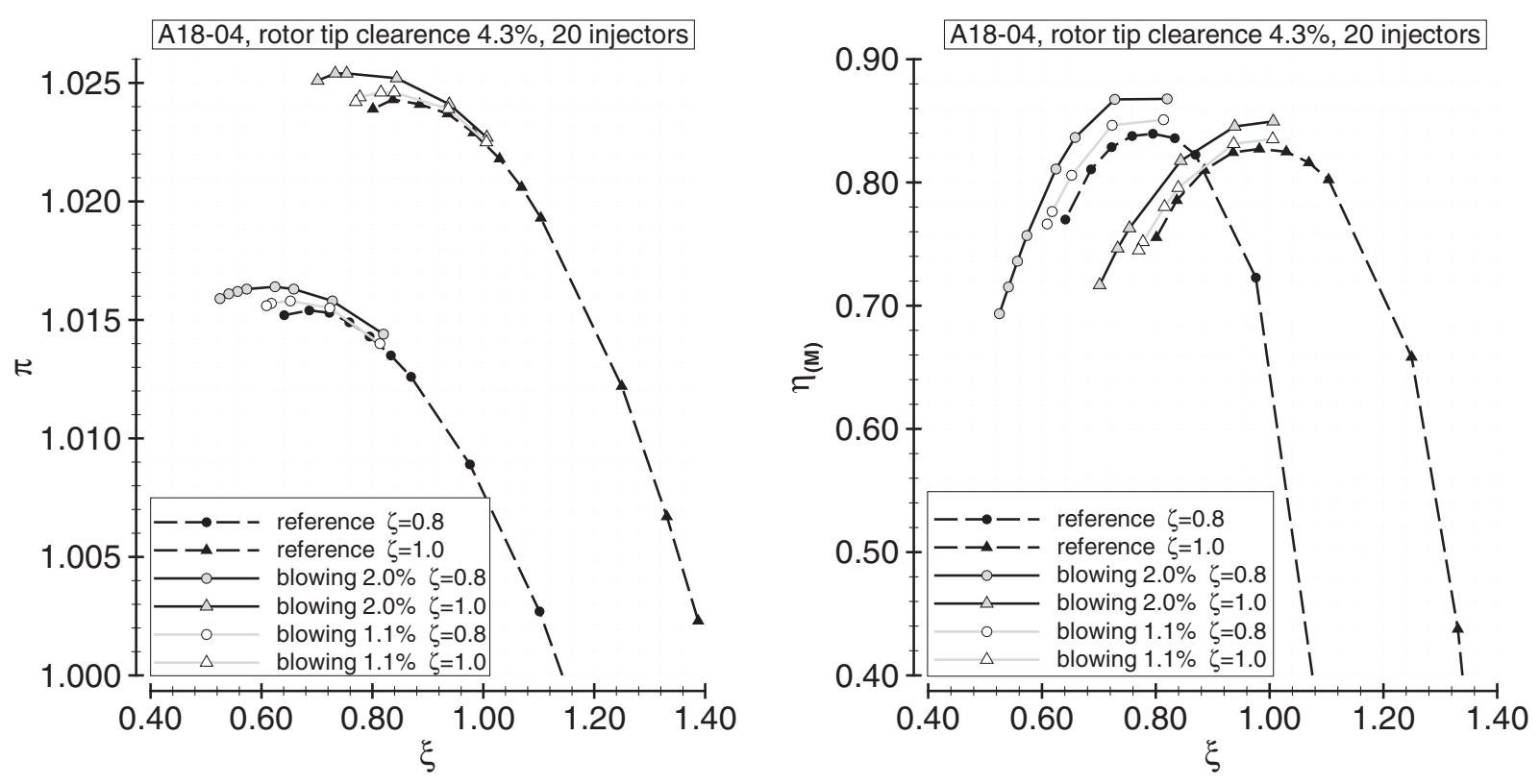

Fig. 2 Characteristics - A18-04

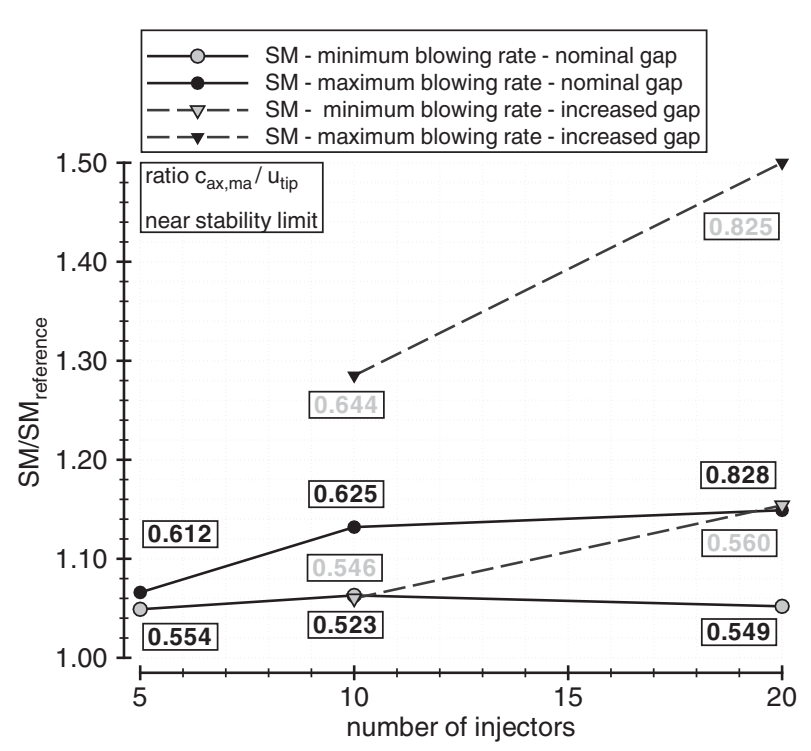

Fig. 3 Benefit in operating range, $\zeta=1.0$

is running with large rotor tip gap. A larger number of injectors leads to a higher extension in operating range by injecting more air with almost the same momentum ratio. Hence, an important parameter is the circumferential coverage of the injectors. Range extension is also proportional to the injected mass flow keeping the number of injectors constant. The maximum range extension for the investigated configurations with an improvement of 50 per cent in surge margin was achieved using 20 injectors and maximum blowing rate of 2 per cent of compressor design mass flow. Tests for recovering the compressor from fully developed stall using injection were not successful. Only by dethrottling, the compressor stability could be recovered.

\subsection{Characteristic of the jet and development over rotor blade row}

The axial velocity component of the incoming jet was measured using a hot wire-probe. The distance between probe and rotor leading edge was about 5.2 per cent of rotor tip chord. Two time steps are exemplarily depicted in Fig. 4 showing results for build A18-01, which is representative for all other configurations. The time scale is related to the rotor blade passing period $t / t_{\text {Rotor }}$. The data are ensemble-averaged over 220 rotor revolutions using a once-per-revolution signal.

The injected mass flow energizes the casing wall boundary layer while increasing the axial velocity component with a peak at 98.5 per cent of channel height (1.8 mm wall distance). The influence of injection is obvious between 94 per cent channel height and casing wall. That means both the nominal and increased rotor tip gaps are completely covered by the incoming jet flow. The fluctuations in the high momentum jet near the casing wall are about 5 per cent of peak velocity and 18 per cent of compressor mean axial velocity in the annular flow path. Hence, with the injector the established Coanda effect as a result of the high-momentum jet is stable and nearly independent from the potential effect of the passing rotor blades. The right part of Fig. 4 shows the time resolved flow field within five rotor revolutions. The local oscillation leads to an apparent 
wavelike inlet flow but is constant over the time with respect to the whole circumference of the compressor. Figure 5 represents the time-averaged distributions of the axial velocity component of build A18-02 and A18-04 (20 injectors) downstream of the rotor blade (approximately 28 per cent of rotor chord at mid span).

It shows that the high peak of momentum due to the injector is almost dissipated. However, there is still a slightly energized casing boundary layer compared to the reference cases without injection.

Detailed flow field measurements were performed for configuration A18-01 using a five-hole probe. The traversing techniques and accuracy are documented in Künzelmann [18]. The right part of Fig. 5 shows the diffusion factor determined from the experimental (Exp.) pitch-averaged data. The numerical time-averaged results (CFD) based on configuration A18-04 with the greatest benefit in operating range enhancement an increased rotor tip gap is shown in Fig. 10. Tip injection decreases incidence at rotor tip gap and hence blade loading. This behaviour could be indicated by the simulations as well. The critical blade loading before stall and thus the surge line can be pushed to lower compressor mass flows. In contrast to the results of Suder et al. [4], the blade with nominal rotor tip gap stalls when the loading at tip reaches a level higher than that for which the blade stalls without injection. Therefore, flow field measurements were carried out at an operating point in the extended operating range (no figure).

\subsection{Stall inception}

The stability behaviour of the Dresden LSRC was extensively investigated by Mailach [20]. Two independent modal waves can be found in the stable operating range of the Dresden LSRC. The modal disturbances can be described by the $1 s t$ and $2 n d$ mode orders. This corresponds to circumferential wavelengths of $360^{\circ}$ and $180^{\circ}$, respectively. The modal waves are associated with wavelike variations of the flow properties (pressure, velocity, blade incidence, etc.) and propagate in circumferential and
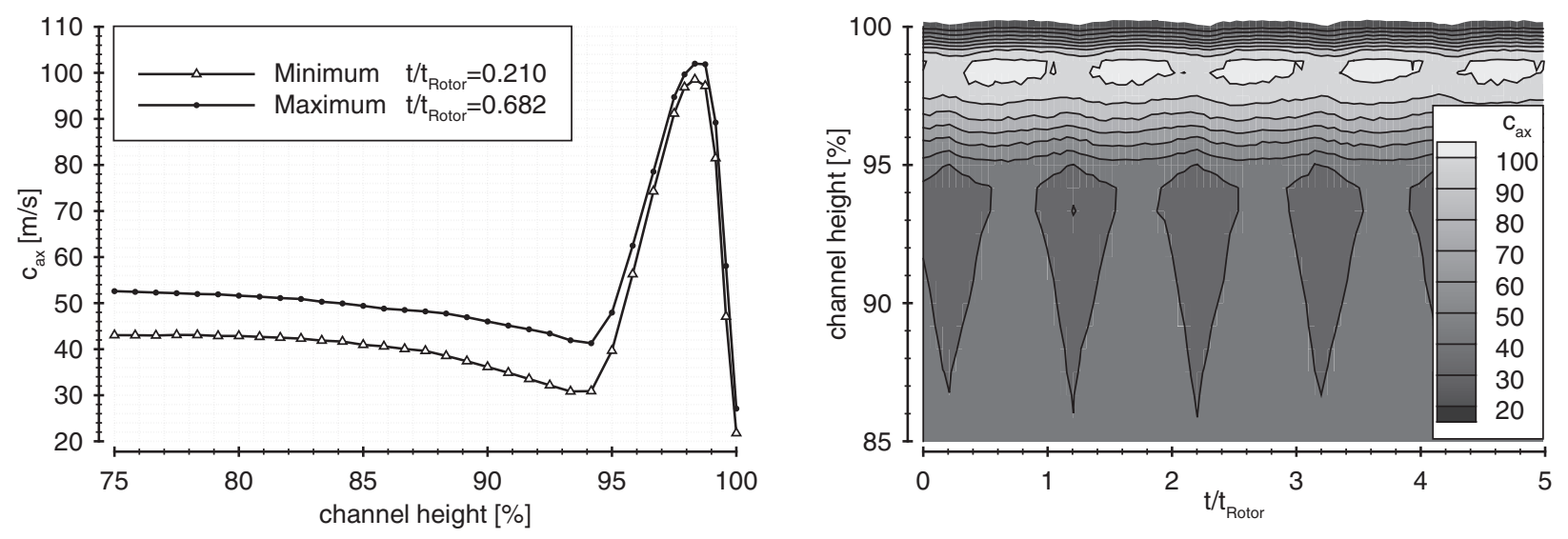

Fig. 4 Distribution of axial velocity upstream of rotor, $\zeta=1.0, \xi=1.0$
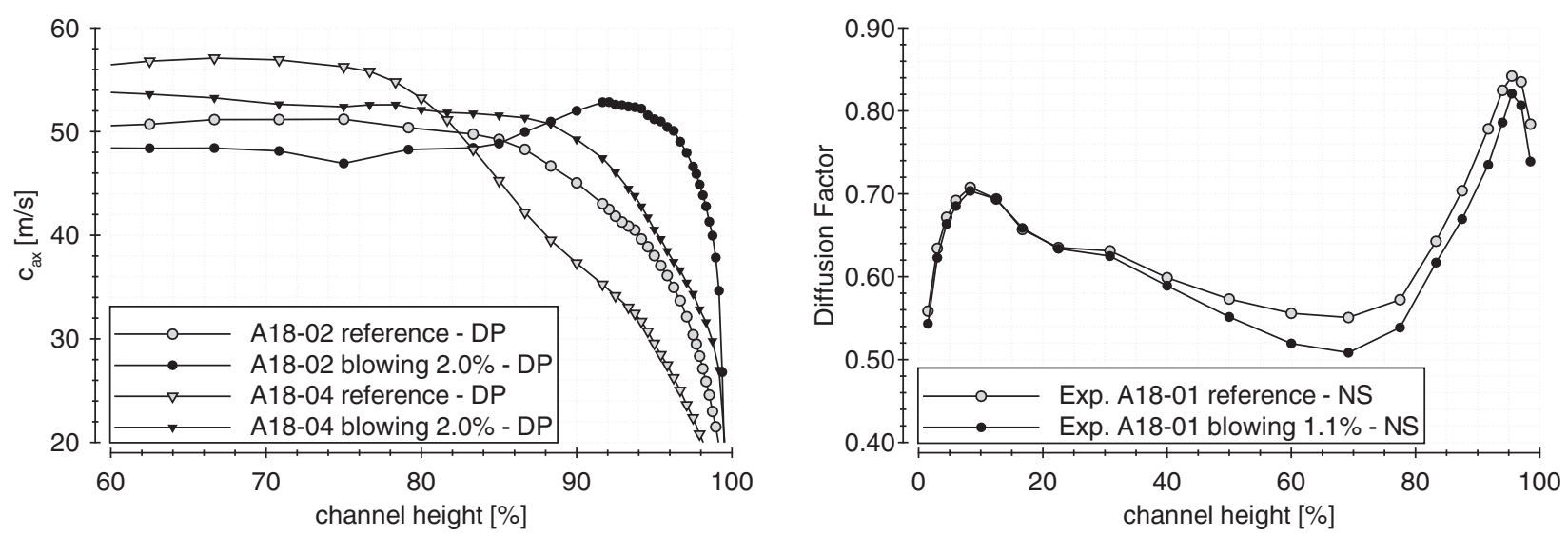

Fig. 5 Distribution of axial velocity downstream of rotor and diffusion factor 
axial directions. The measurements discussed in this article were performed using 12 microphones, which were uniformly distributed around the compressor casing next to the rotor leading edge.

The fundamental mechanism of stall inception with and without blowing is the same for the 1.5-stage compressor as for the standard 4.5-stage compressor documented in Mailach and Vogeler [21]. Just before the stability limit, the two modal

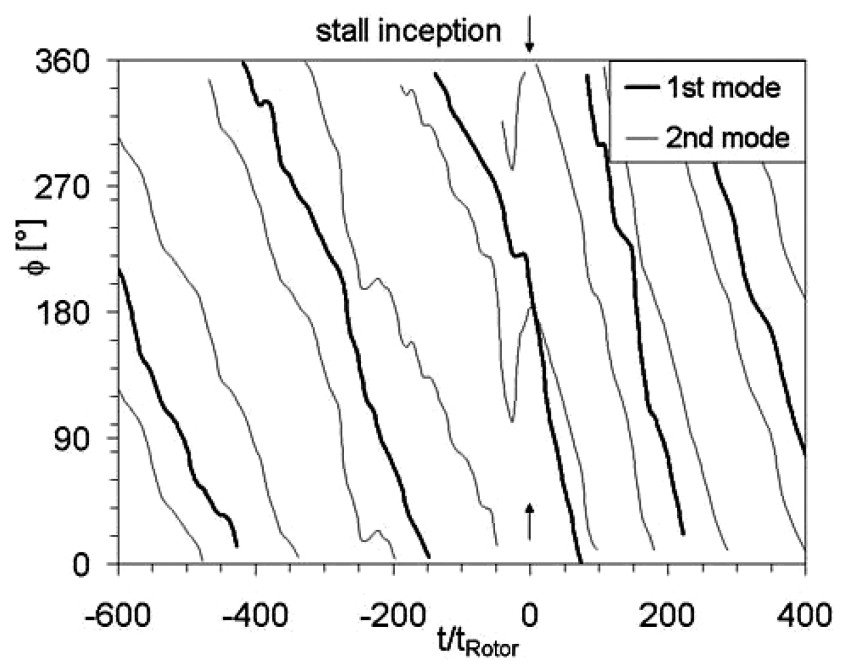

Fig. 6 Stall inception - A18-02 reference
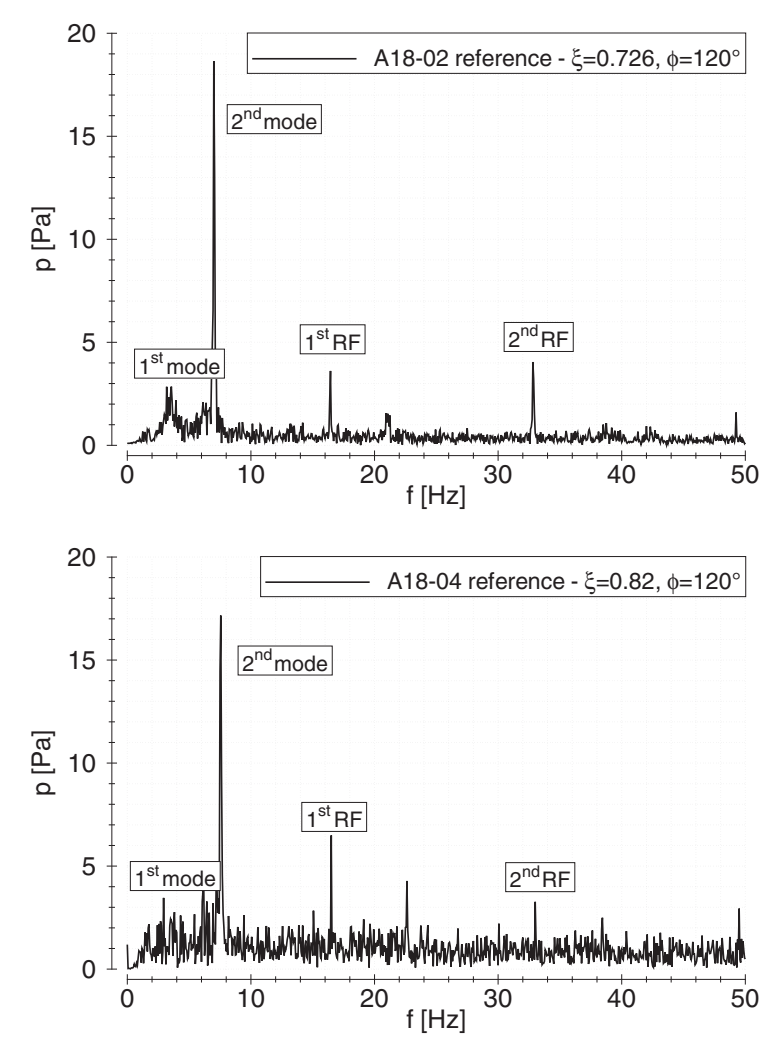

waves superimpose, while their amplitudes increase. As a typical example, the propagation of the of the $1 s t$ and $2 n d$ modes along the compressors circumference $(\phi)$ and the stall inception, based on a spatial reconstructed signal of the microphone array (pressure maxima of modal waves), is shown in Fig. 6 .

Figure 7 shows the frequency spectra of the configurations A18-02 and A18-04 (20 injectors) with and without blowing near stability limit. The data are derived from the same sensor. The strongest influence is given by the 2nd mode with the highest amplitudes. The 1st mode is close to a region of low-frequency noise and will not be discussed. Further, the 1st and 2nd RF can be recognized. With present injection, the 2nd mode can be damped significantly running the compressor with nominal as well as increased rotor tip gap. This phenomenon is independent of the circumferential position.

Stall cells directly develop from superimposed modal waves. The effect of blowing is that this critical condition of the modes can be pushed to lower total mass flows leading to an improved stability.

\section{NUMERICAL INVESTIGATIONS}

The main intention of performing CFD calculations was to investigate the global flow field to compare the
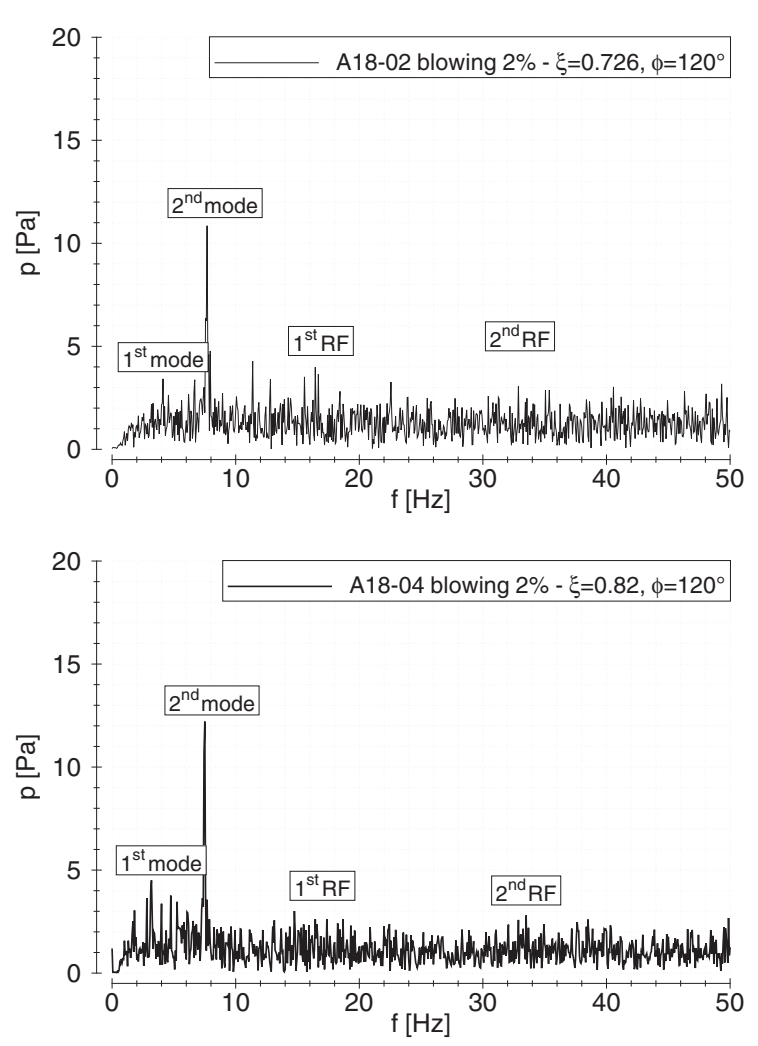

Fig. 7 Frequency spectra and impact of blowing, $\zeta=1.0$ 
data to the experimental results and to have access to the information of the flow field in the rotor passage.

No simplification of the original geometry has been made, except for the inlet nozzle and the outlet diffuser, which were neglected to reduce calculation time. Hence, experimental data were required for boundary conditions at the computational domain inflow and outflow. The block topology is based on configuration A18-04 with increased rotor tip gap shown in Fig. 8, Urban [22].

The model consists of only one blade/vane per row with periodic boundary conditions in the circumferential direction, the injector domain and the plenum with the secondary inlet. A rotor-stator interface is applied between the rows and another one between the rotating supply blocks and the blowing domain in the absolute frame of reference. Further, two supply blocks are added to the blowing domain in the circumferential direction to represent the real periodicity. For this reason, a time-resolved procedure of calculation is used. Prior CFD studies have shown, that flow injection is damped uniformly over the circumference using steady methods caused by the mixing plane (pitch-averaging). As a result, the flow physics leading to an improved stability cannot be captured. The unsteady simulations were performed using NLH integrated in the flow solver provided by NUMECA [23]. The benefit is the reduced calculation time compared to real-time solvers and to keep the real pitches of the rows and injectors and hence the frequencies. That is an advantage compared to domain scaling methods which leads to changes in pitch and stagger angle to keep the aerodynamic loading of the blades. The 3D mesh consists of structured blocks and it has a high density near the wall region $\left(y^{+}<5\right)$ where the low Re Spalart-Allmaras turbulence model is used. The first inner cell has a width of $0.01 \mathrm{~mm}$. The grid point distribution is 105 in radial direction with 25 grid lines in the rotor tip gap and a total number of about 6 million grid points. The working fluid is air as ideal gas. The walls are treated adiabatic. The numerical accuracies are as follows: a central spatial discretization scheme of 2nd and 4th orders of Jameson was used and an explicit four-stage Runge-Kutta discretization scheme in time. The type of the rotor-stator interface is a full non-matching mixing plane. The simulations are considered to be converged when the global residual is less than -5.0 , the error in the mass flow balance is below 0.01 per cent and fluxes achieved equilibrium.

To determine the characteristic at design speed $(\zeta=1.00)$, every unsteady calculated operating point converged using total-to-static pressure boundary conditions at the inlet and outlet domains. To throttle the compressor model, the static backpressure was adjusted using decreased steps near stability limit.

The right part of Fig. 8 shows the distribution of axial velocity upstream of the rotor at the same axial position compared to the experimental investigations. The time-scale is related to the rotor blade passing period. The predicted flow field is qualitatively comparable to the experimental data, shown before in Fig. 4. The maximum jet velocity is 18 per cent overestimated and located closer to wall with a peak at 99.4 per cent of channel height. The periodic perturbations are predicted well compared to the experiments.

The compressor characteristic was calculated using a medium mesh resolution but keeping the mesh density adequately to the requirements of the NLH approach. The enhanced operating range regarding the total compressor mass flow is similar compared to the experimental results shown in Fig. 9. The reduction of total mass flow is about 14.5 per cent relative to the reference calculation at the last stable operating point. The pressure ratio of the reference
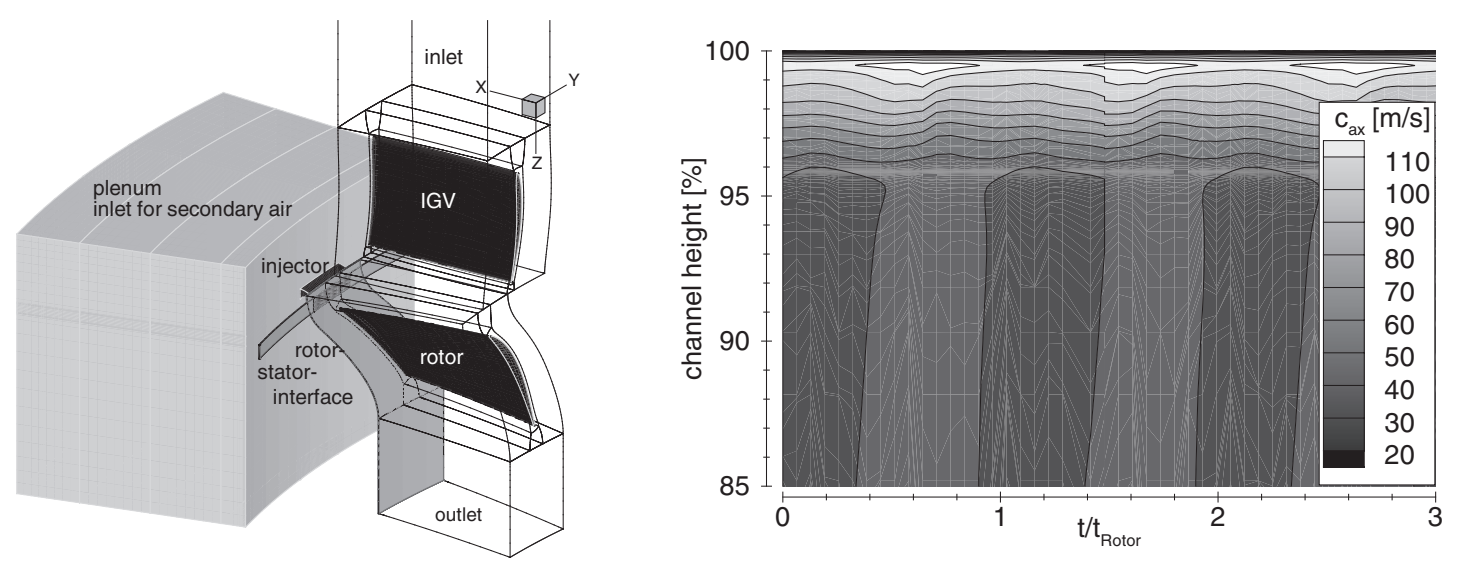

Fig. 8 Block topology and distribution of axial velocity upstream of rotor, DP 
model is overestimated but the characteristic of the blowing model near stability limit is closer to the experimental results.

Figure 10 shows the diffusion factor determined from the numerical time-averaged results (CFD). The unloading of the blades increases significantly with larger rotor tip clearance and present tip injection. The blade with increased rotor tip gap stalls

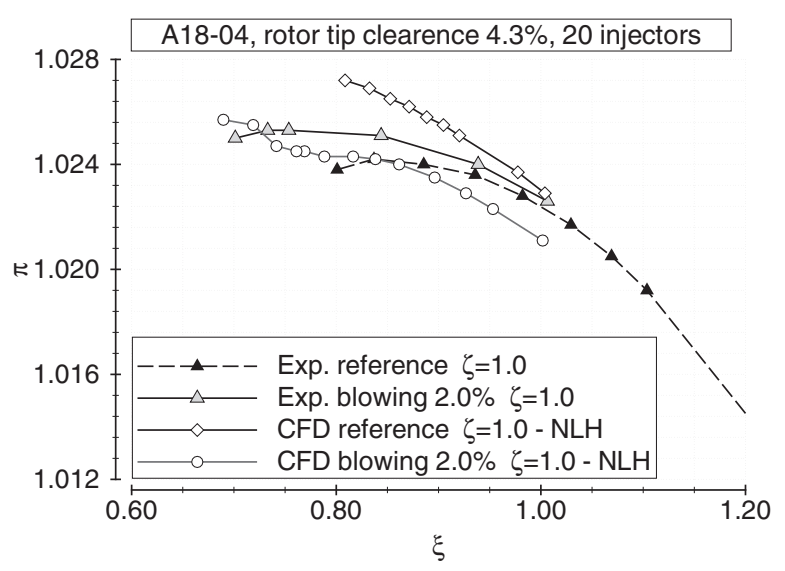

Fig. 9 Comparison of compressor characteristics

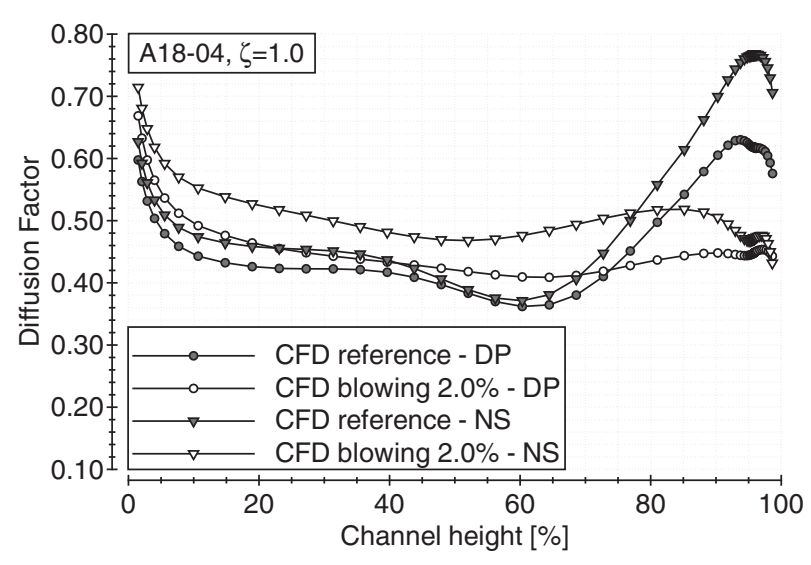

Fig. 10 Distribution of diffusion factor of rotor when the loading at tip reaches a level lower than that for which the blade stalls without injection. The last stable operating point with injection in the extended operating range shows that the loading over the whole rotor blade is increasing. The difference in loading at the rotor tip between design point and stability limit is much more higher without injected mass flow.

A cylindrical cross-section at mid-height of the rotor tip gap shows the streamlines based on the relative velocity and the development of the rotor tip vortex at a certain time step. The reference model shows the periodic development of the tip vortex which is the same for the adjacent blade, Fig. 11. This behaviour changes with tip injection. The flow field and the development of the tip vortex are periodically disturbed and weakened. While passing an injector in the absolute frame of reference, the vortex is pushed in axial direction and it does not impact the pressure side of the adjacent blade, Fig. 12. This influence is coupled with the previously discussed damping of the modal waves and reduction of global loss with the effect of enhanced stability and operating range.

\section{CONCLUSIONS}

Experiments and CFD simulations have shown that stability enhancement can be achieved by air injection through discrete wall jets upstream of a tip-critical subsonic compressor. Injection is also effective to improve the characteristics of efficiency during part and full speed, especially for the configurations with increased rotor tip gap.

Furthermore, it could be demonstrated that the fundamental mechanism of stall inception with and without blowing is the same for the 1.5-stage compressor as for the standard 4.5-stage compressor. The blowing results in a damping of the dominant modal wave which appear as a stall precursor in the Dresden LSRC.

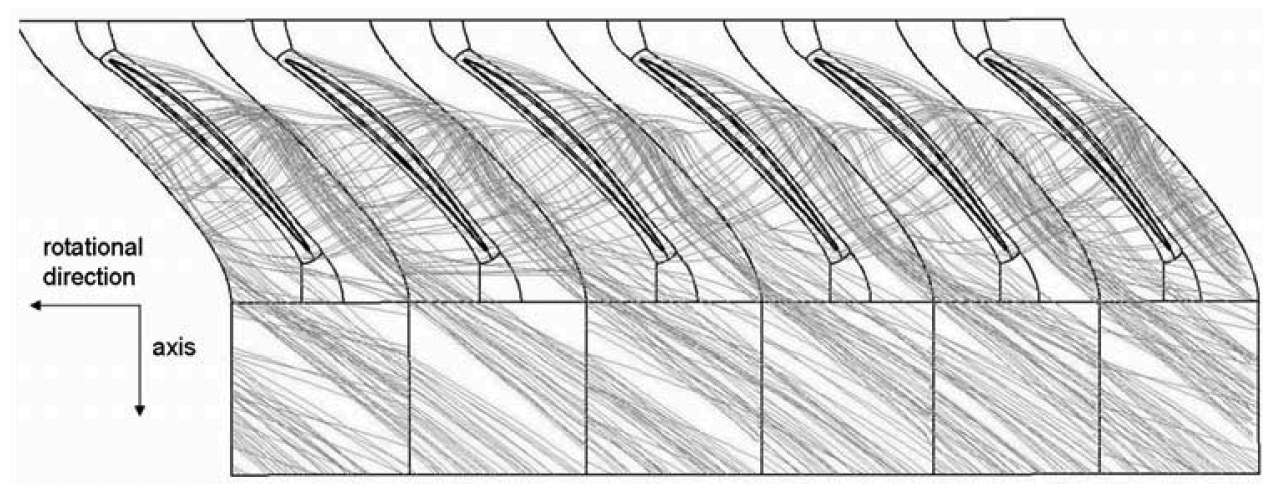

Fig. 11 Development of tip vortex - A18-04 reference, $\zeta=1.0, \xi=0.922$ 


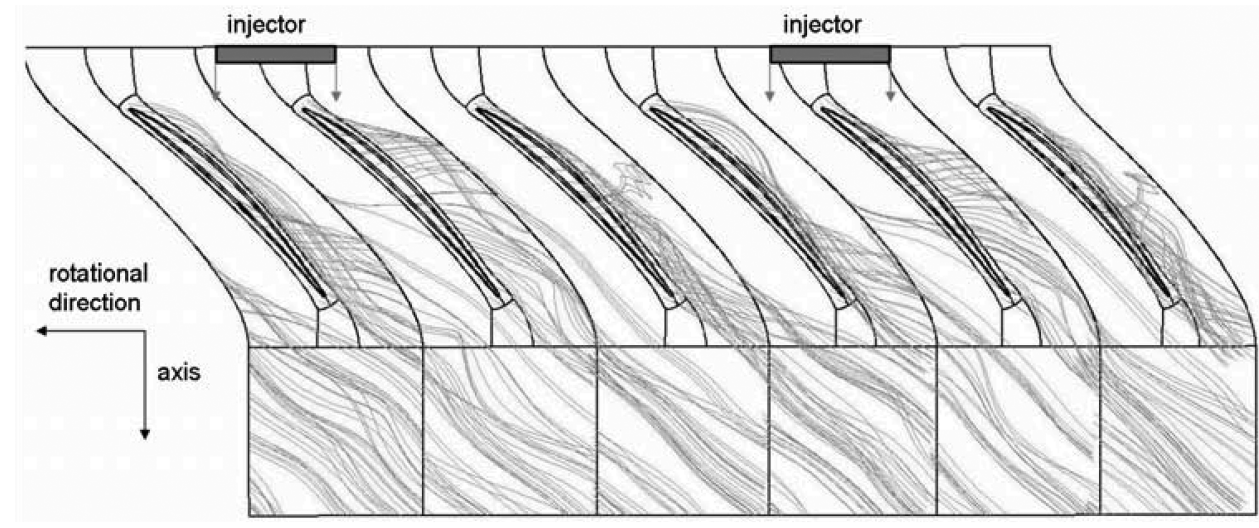

Fig. 12 Development of tip vortex - A18-04 blowing 2 per cent, $\zeta=1.0, \xi=0.922$

The CFD calculations were able to capture the global flow physics and to predict the improvement in stability enhancement. The numerical results show that the development of the tip vortex is strongly influenced by the tip injection which leads to decreased global loss and loading and an enhanced operating range.

In summary, the last stable operating point can be pushed to lower total mass flows as a result of the delay of stall inception. For the investigated compressor setup, the following fundamental conclusions can be drawn.

1. Tip injection decreases incidence and hence blade loading at the tip for nominal as well as increased rotor tip gap. Within the extended operating range, the blade loading increases compared to the operating points of the nominal mass flow range while the compressor works on a stable operating point.

2. The extension of operating range is correlated with the increase in mass-averaged axial velocity at the rotor tip and related to the circumferential coverage of injection (compare Suder et al., 2001).

3. A large rotor tip gap increases the global loss compared to nominal clearance. With the tip injection a clear benefit in efficiency of the large tip clearance configuration is achieved.

4. Using injection, the rotor tip vortex is periodically affected. This also results in a damping of the modal waves, which leads to an enhanced stability of the compressor.

\section{ACKNOWLEDGEMENTS}

The authors would like to thank Rolls-Royce Deutschland for their support and permission to publish this study. The investigations were conducted as a part of the research program LuFoIII. The responsibility for the content lies solely with its authors.

\section{(C) Authors 2011}

\section{REFERENCES}

1 Mattiske, B. Experimentelle Untersuchung einer mehrstufigen Axialverdichterbeschaufelung mit Randzonenkorrektur, Fortschrittberichte VDI, Reihe 7, Nr. 252, Hannover, 1994.

2 Wilde, G. L. Improvements in or relating to gas turbines. British Patent $(701,576)$, filed 28 June 1950.

3 Koch, C. C. and Smith Jr., L. H. Experimental evaluation of outer casing blowing or bleeding of single stage axial compressor, Part IV-Performance of bleed insert configurations No. 3, NASA CR-54590, 1968.

4 Suder, K. L., Hathaway, M. D., Thorp, S. A., Strazisar, A. J., and Bright, M. B. Compressor stability enhancement using discrete tip injection. ASMEJ. Turbomach., 2001, 123, 14-23.

5 Weigl, H. J., Paduano, J. D., Frechette, L. G., Epstein, A. H., Greitzer, E. M., Briht, M. M., and Strazisar, A. J. Active stabilization of rotating stall and surge in a transonic single-stage axial compressor. ASME J. Turbomach., 1998, 120, 625-636.

6 Epstein, A. H., Ffowcs Williams, J. E., and Greitzer, E. M. Active suppression of aerodynamic instabilities in turbomachines. ASME J. Propuls. Power, 1986, 5, 204-211.

7 Day, I. J. Active suppression of rotating stall and surge in axial compressors. ASME J. Turbomach., 1993, 115, 40-47.

8 Day, I. J. Stall inception in axial flow compressors. ASME J. Turbomach., 1993b, 115, 1-9.

9 D'Andrea, R., Behnken, R. L., and Murray, R. M. Rotating stall control of an axial flow compressor using pulsed air injection. ASME J. Turbomach., 1997, 119, 742-752.

10 Strazisar, A. J., Bright, M. M., Thorp, S., Culley, D. E., and Suder, K. L. Compressor stall control through endwall recirculation. ASME Paper No. GT200454295, 2004.

11 Ffowcs Williams, J. E., Harper, M. F. L., and Allwright, D. J. Active stabilization of compressor instability and surge in a working engine. ASME J. Turbomach., 1993, 115, 68-75. 
12 Freeman, C., Wilson, A. G., Day, I. J., and Swinbanks, M. A. Experiments in active control of stall on an aeroengine gas turbine. ASME J. Turbomach., 1998, 120, 637-647.

13 Scheidler, S. G. and Fottner, L. Experimental operating range extension of a twin-spool turbofan engine by active stability control measures. ASME J. Eng. Gas Turb. Power, 2006, 128, 20-28.

14 Bindl, S., Stößel, M., and Niehuis, R. Stall detection within the low pressure compressor of a twin- spool turbofan engine by tip flow analysis. ASME Paper No. GT2009-59032, 2009.

15 Hathaway, M. D. Passive endwall treatments for enhancing stability. Von Kármán Institute for Fluid Dynamics (VKI), Lecture Series 2006-06, Advances in Axial Compressor Aerodynamics, 15-18 May 2006, Rhode-Saint-Genèse, Belgium, 2006.

16 Sauer, H., Bernstein, W., Bernhard, H., Boos, P., and Möckel, H. K. Fertigung und Aufbau eines Verdichterprüfstandes und Aufnahme des Versuchsbetriebes an einem NiedergeschwindigkeitsAxialverdichter in Dresden. Abschlußbericht zum BMBF-Vorhaben 0326758A, Dresden, Germany, 1996.

17 Boos, P., Möckel, H., Henne, J. M., and Selmeier, R. Flow measurement in a multistage large scale low speed axial flow research compressor. ASME Paper No. 98-GT-432, 1998.

18 Künzelmann, M., Müller, R., Mailach, R., and Vogeler, K. Steady and unsteady flow field in a multistage low-speed axial compressor -a test case. ASME Paper no. GT2008-50793, 2008.

19 Cumpsty, N. Compressor aerodynamics, 2004 (Krieger Publishing Company, Malabar, Florida).

20 Mailach, R. Experimentelle Untersuchung von Strömungsinstabilitäten im Betriebsbereich zwischen Auslegungspunkt und Stabilitätsgrenze eines vierstufigen Niedergeschwindigkeits-Axialverdichters. (Dissertation, Technische Universität Dresden), Fortschritt-Berichte VDI, Reihe 7, Nr. 410, VDI-Verlag, Düsseldorf, Germany, 2001.

21 Mailach, R. and Vogeler, K. Unsteady aerodynamic blade excitation at the stability limit and during rotating stall in an axial compressor. ASME J. Turbomach., 2007, 129, 503-511.

22 Urban, R. Numerische Untersuchungen an einem 1.5 stufigen Axialverdichter mit aktiver Strömungskontrolle. Diploma Thesis, Institut für Strömungsmechanik, Technische Universität Dresden, Germany, 2010.

23 NUMECA INTERNATIONAL. License and user manual FINETM/Turbo v7 (including Euranus). Documentation v7a, Brussels, 2006.

\author{
APPENDIX

\section{Notation} \\ c velocity $[\mathrm{m} / \mathrm{s}]$ \\ $h \quad$ enthalpy $[\mathrm{J} / \mathrm{kg}]$ \\ $\dot{m} \quad$ mass flow $[\mathrm{kg} / \mathrm{s}]$ \\ $n \quad$ rotational speed $[\mathrm{r} / \mathrm{min}]$ \\ $p \quad$ pressure $[\mathrm{Pa}]$ \\ $P_{(M)} \quad$ mechanical power [W] \\ $R \quad$ ideal gas constant $[\mathrm{J} / \mathrm{kg} \mathrm{K}]$ \\ $t$ time [s] \\ $t_{\text {Rotor }}$ rotor passing period [s] \\ $T$ temperature [K] \\ $u_{\text {tip }} \quad$ rotor tip velocity $[\mathrm{m} / \mathrm{s}]$ \\ $\mathrm{x}, \mathrm{y}, \mathrm{z}$ coordinates [m] \\ $y^{+} \quad$ wall distance \\ $\eta_{(M)}$ efficiency \\ $\kappa \quad$ specific heat $[\mathrm{J} / \mathrm{kg} \mathrm{K}]$ \\ $\pi \quad$ total pressure ratio \\ $\zeta \quad$ speed coefficient \\ $\xi \quad$ flowrate coefficient \\ $\phi \quad$ circumference $\left[{ }^{\circ}\right]$
}

\section{Abbreviations}

CFD computational fluid dynamics

DP design point

Exp. experiment

IGV inlet guide vane

LSRC low speed research compressor

MS mid span

NLH non-linear harmonic

NS near stability limit

RF rotor frequency

SAS secondary air system

SM surge margin

\section{Subscripts}

$\begin{array}{ll}\text { ax } & \text { axial } \\ \text { in } & \text { inlet } \\ \text { inj } & \text { injected } \\ \text { ma } & \text { mass averaged } \\ \text { out } & \text { outlet } \\ \text { pl } & \text { plenum } \\ \text { s } & \text { isentropic } \\ \text { t } & \text { total }\end{array}$

